University of Massachusetts Amherst

ScholarWorks@UMass Amherst

2018

\title{
Structural and Optical Properties of Nanocrystalline TiO2 with Multiwalled Carbon Nanotubes and Its Photovoltaic Studies Using $\mathrm{Ru}(\mathrm{II})$ Sensitizers
}

Sagar D. Delekar

Florida State University

Ananta G. Dhodamani

Shivaji University

Krantiveer V. More

Shivaji University

Tukaram D. Dongale

Shivaji University

Rajanish K. Kamat

Shivaji University

See next page for additional authors

Follow this and additional works at: https://scholarworks.umass.edu/chem_faculty_pubs

\section{Recommended Citation}

Delekar, Sagar D.; Dhodamani, Ananta G.; More, Krantiveer V.; Dongale, Tukaram D.; Kamat, Rajanish K.; Acquah, Steve; Dalal, Naresh S.; and Panda, Dilip K., "Structural and Optical Properties of Nanocrystalline TiO2 with Multiwalled Carbon Nanotubes and Its Photovoltaic Studies Using Ru(II) Sensitizers" (2018). ACS Omega. 1454.

http://dx.doi.org/10.1021/acsomega.7b01316 


\section{Authors}

Sagar D. Delekar, Ananta G. Dhodamani, Krantiveer V. More, Tukaram D. Dongale, Rajanish K. Kamat, Steve Acquah, Naresh S. Dalal, and Dilip K. Panda 


\title{
Structural and Optical Properties of Nanocrystalline $\mathrm{TiO}_{2}$ with Multiwalled Carbon Nanotubes and Its Photovoltaic Studies Using Ru(II) Sensitizers
}

\author{
Sagar D. Delekar, ${ }^{*}, \dagger, \dagger, \| \odot$ Ananta G. Dhodamani, ${ }^{\#, \dagger}$ Krantiveer V. More, ${ }^{\dagger}$ Tukaram D. Dongale, ${ }^{\ddagger}$ \\ Rajanish K. Kamat, ${ }^{\S}$ Steve F. A. Acquah, ${ }^{\|}$Naresh S. Dalal, ${ }^{\| \odot}$ and Dillip K. Panda ${ }^{*}, \|, \perp$ \\ ${ }^{\dagger}$ Department of Chemistry, Shivaji University, Kolhapur, 416004 MS, India \\ "Computational Electronics and Nanoscience Research Laboratory, School of Nanoscience and Biotechnology, Shivaji University, \\ Kolhapur, 416004 MS, India \\ ${ }^{\S}$ Department of Electronics, Shivaji University, Kolhapur, 416004 MS, India \\ "Department of Chemistry and Biochemistry, Florida State University, Tallahassee, Florida 30306-4390, United States \\ ${ }^{\perp}$ Department of Chemistry, Clemson University, Clemson, South Carolina 29634, United States
}

Supporting Information

\begin{abstract}
In this study, the in situ sol-gel method has been deployed to prepare the titanium dioxide/multiwalled carbon nanotubes $\left(\mathrm{TiO}_{2} / \mathrm{MWCNTs}\right)$ nanocomposite (NCs) powders with varying content of MWCNTs (0.01-1.0 wt \%), to construct the dye-sensitized solar cells (DSSCs). First, binder-free NCs were deposited on a transparent-conducting $\mathrm{F}: \mathrm{SnO}_{2}$ (FTO) glass substrate by a doctor-blade technique and then anchored with $\mathrm{Ru}(\mathrm{II})$-based dyes to either N719 or ruthenium phthalocyanine $(\mathrm{RuPc})$. The structural and optical properties and interconnectivity of the materials within the composite are investigated thoroughly by various spectral techniques (XRD, XPS, Raman, FTIR, and UV-vis), electron microscopy (HRTEM), and BET analysis. The experimental results suggest that the ratio of MWCNTs and $\mathrm{TiO}_{2}$ in NCs, morphology, and their interconnectivity influenced their structural, optical, and photovoltaic properties significantly. Finally, the photovoltaic performances of the assembled DSSCs with different content of MWCNTs to $\mathrm{TiO}_{2}$ films anchored with two different dyes were tested under one sun irradiation $\left(100 \mathrm{~mW} / \mathrm{cm}^{2}\right)$. The measured current-voltage $(I V)$ curve and incident photon-to-current conversion efficiency (IPCE) spectra of $\mathrm{TiO}_{2} / 0.1$ wt \% MWCNTs (T@0.1 C) for N719 dye show three times more power conversion efficiency $(\eta=6.21 \%)$ which is opposed to an efficiency $(\eta=2.07 \%)$ of T@0.1 C for $\mathrm{RuPc}$ dye under the same operating conditions.
\end{abstract}

\section{INTRODUCTION}

Solar energy has become one of the fastest growing industries among all current energy industries. Among the various renewable energy sources, sunlight energy is the largest global energy source and reaches the earth's surface at an average of $4.3 \times 10^{20} \mathrm{~J} \mathrm{~h}^{-1}$, which is equal to the annual energy demand of today's society. A few generations of solar cell research are already in place for the fabrication of solar cells that convert solar light to electrical power. ${ }^{2,3}$ However, for the last two decades, dye-sensitized solar cells (DSSCs) seem to be one of the most promising, due to their low cost, easy construction and also generate comparable power conversion efficiency to silicon solar cells. ${ }^{4}$ In brief, DSSCs consist of two electrodes, namely, working electrodes (dye-coated semiconductors) and counter electrodes (platinized ITO glass) having an organicbased redox electrolyte $\left(\mathrm{I}^{-} / \mathrm{I}_{3}^{-}\right)$between these two electrodes. Most of the research has focused on either using a semiconductor $\mathrm{TiO}_{2}$ or various ruthenium(II) $[\mathrm{Ru}(\mathrm{II})]$ based dyes. ${ }^{5}$ However, the other critical parameters, such as electron density, the mobility of charge carriers, right alignment of energy levels (HOMO and LUMO) of the dye, or redox mediator with respect to valence band and conduction band energy level of the semiconductor, also play a pivotal role in the enhancement of photovoltaic performance of DSSCs. ${ }^{6}$ However, the power conversion efficiency $(\eta)$ of these devices has reached up to $14.5 \%{ }^{7}$ This efficiency is less as compared to the $S-Q$ limit (theoretical efficiency of $34 \%$ for a single $p-n$ junction $)^{8}$ of DSSCs or nanomaterial-based solar devices (theoretical efficiency up to 66\%). ${ }^{9}$ Therefore, the devices with modified $\mathrm{TiO}_{2}$ (varied in optical and electronic) electrode, anchored with various $\mathrm{Ru}(\mathrm{II})$ sensitizers (either N719 or

Received: September 6, 2017

Accepted: December 25, 2017

Published: March 7, 2018 

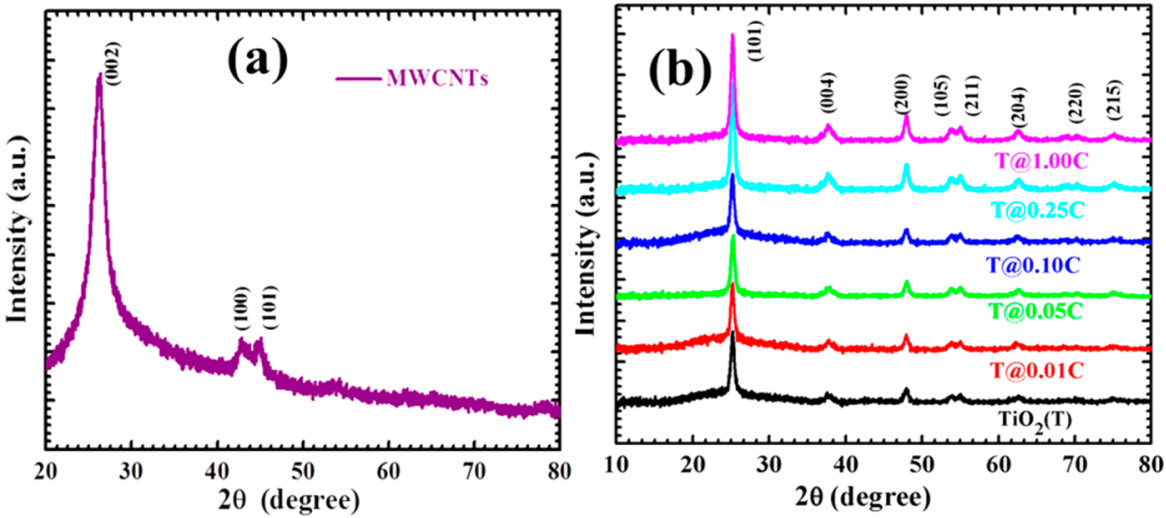

Figure 1. XRD patterns of (a) MWCNTs and (b) bare $\mathrm{TiO}_{2} \mathrm{NPs}$ and $\mathrm{TiO}_{2} / \mathrm{MWCNTs}$ NCs with varying content of MWCNTs from 0.01 to 1.0 wt $\%$.

$\mathrm{RuPc})$, would benefit from harvesting more photons from a broad range of the solar spectrum.

Various strategic synthetic routes have been employed, such as doping, ${ }_{10}^{10}$ supported with metal/metal oxides, ${ }^{11}$ or composites, $^{12}$ to tune the optical, electrical, porosity, and structure-induced morphology of $\mathrm{TiO}_{2}$; however, importance has been placed on preparing the visible active composites of $\mathrm{TiO}_{2}$ nanoparticles (NPs) with highly conducting MWCNTs. ${ }^{13}$ $\mathrm{TiO}_{2}$-MWCNTs NCs research has focused more on design of the electrode for solar energy harvesting materials. The reported synthesis of $\mathrm{TiO}_{2} /$ MWCNTs NCs requires high temperature, expensive chemicals, and materials, and moreover, their nonuniform morphology lowers the performance as working electrode materials. Earlier, Wang et al. synthesized $\mathrm{TiO}_{2} /$ MWCNTs nanohybrids by a single-step laser pyrolysis technique via both in situ and ex situ ways. However, DSSC efficiencies comprised of these electrodes were limited to only $3.9 \%$ and $3.3 \% .{ }^{14}$ Moreover, the pyrolysis techniques always require state-of-the-art advanced and expensive equipment which is not desirable for photovoltaic technology. ${ }^{15}$ Mahmood et al. reported the DSSC efficiency of 5.25\% using 0.06 wt \% MWCNTs along with commercially purchased $\mathrm{TiO}_{2}$ paste. These photoelectrodes were prepared by mixing MWCNTs in ethanol with the $\mathrm{TiO}_{2}$ paste using the sonochemical method. ${ }^{16}$ However, MWCNTs not uniformly decorated with $\mathrm{TiO}_{2}$ particles by this technique were confirmed by TEM analysis. The use of only bare MWCNTs always retards the electron transport between the semiconducting photoelectrode to the counter electrode, overall decreasing the power conversion efficiency of the cells. A high-temperature hydrothermal synthesis of $\mathrm{TiO}_{2} /$ MWCNTs NCs was also reported and resulted in the device efficiency of up to $7.37 \%$, which is higher than that of bare $\mathrm{TiO}_{2} \mathrm{NPs}$ as well as Degussa P25 NPs. ${ }^{17}$ The 5 wt \% MWCNTs content composites of $\mathrm{TiO}_{2} /$ MWCNTs thin films prepared by an electrospinning technique reported a greater efficiency. ${ }^{18}$ The agglomeration is the key problem of this kind of $\mathrm{TiO}_{2} / \mathrm{MWCNTs}$ NCs. These NCs also absorb the incident photons actively which retard the electron-hole separation and lower the photovoltaic performance. ${ }^{19}$ Also, the electrospinning technique always produces the irregular and nonuniform morphology structure within the NCs which often results in low power energy conversion efficiencies.

$\mathrm{Ru}(\mathrm{II})$-based sensitizers have played a significant role in the development of the solar cells as a chromophore. The efficiency of the DSSCs could be improved significantly if these dyes have absorption in the range of visible to NIR of the solar spectrum. $^{20}$ Researchers have studied various chromophores including metal complexes and organic-based dyes. Among all dyes, $\mathrm{Ru}(\mathrm{II})$ polypyridine-based sensitizers, mainly black dye, N3, and N719, are the better chromophores for DSSCs due to their promising chemical and photochemical stability along with enhanced photovoltaic performance. ${ }^{21}$ Similarly, the RuPc dye is also used as an alternative dye for DSSCs due to its analogues to N719 dye's structure, chemical and photochemical stability, and high molar extinction coefficient. Indeed, this intrinsic nature of $\mathrm{RuPc}$ dye promotes harvesting of more photons in the entire range of the visible to NIR solar spectrum. Also, the suitable electrochemical redox property of $\mathrm{RuPc}$ is utilized as a promising dye to anchor semiconducting metal oxides $\left(\mathrm{TiO}_{2}\right)$ for other applications. ${ }^{22}$

In this work, we report the synthesis of $\mathrm{TiO}_{2} / \mathrm{MWCNTs}$ NCs with varying content of MWCNTs by in situ sol-gel method, and then these materials are well characterized by various spectroscopies (XRD, XPS, UV-vis, PL, FT-IR, and Raman), microscopy techniques (HRTEM), and BET measurements for knowing their structural, morphological, and optical properties. Thereafter, these materials are deposited on FTO glass substrates by a doctor blade technique to form the photoelectrodes. Finally, the photovoltaic performances of the assembled sandwiched devices made of a different composite of $\mathrm{TiO}_{2} /$ MWCNTs are measured (IV and IPCE) under one sun condition $\left(100 \mathrm{~mW} / \mathrm{cm}^{2}\right)$ and compared with two different dyes (N719 and RuPc).

\section{RESULTS AND DISCUSSION}

The thermal stability and existence of MWCNTs in the NC samples were studied by using thermogravimetric analysis (TGA) and illustrated in the Supporting Information (Figure S1, SI). The crystal structure of the pure phase of the materials (MWCNTs, bare $\mathrm{TiO}_{2}$ NPs, and $\mathrm{TiO}_{2} /$ MWCNTs NCs) was characterized by using a Powder X-ray diffraction (XRD) technique. XRD pattern of MWCNTs (Figure 1(a)) shows a sharp peak at 26.17 corresponding to a (002) reflection, confirming the presence of elemental carbon (JCPDS No. 411487). XRD patterns of $\mathrm{TiO}_{2}$ and different $\mathrm{TiO}_{2} /$ MWCNTs NCs are presented in Figure 1(b). The various peaks observed at 25.21 (101), 37.63 (004), 47.90 (200), $\sim 53.89$ (105), $\sim 55.03$ (211), $\sim 62.57$ (204), $\sim 69.98$ (220), and $\sim 74.93(215)$ are the characteristic peaks of anatase $\mathrm{TiO}_{2}$ (JCPDS No. 211272). The sharp, intense peaks of the samples reveal the crystalline nature with crystallite size in the range between 15 

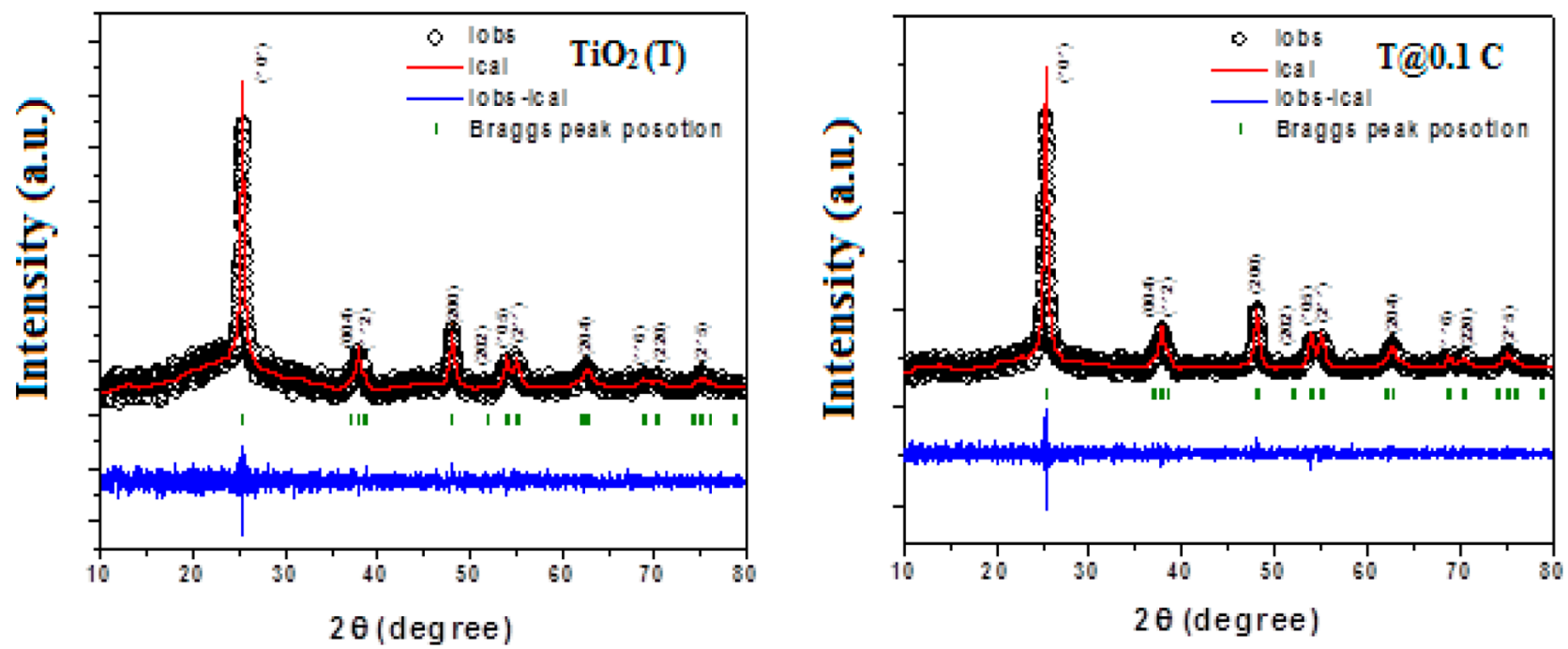

Figure 2. XRD Rietveld refined patterns of (a) bare $\mathrm{TiO}_{2} \mathrm{NPs}$ and (b) T@0.1C NCs.

Table 1. Rietveld Refinement Factors of $\mathrm{Bare}^{\mathrm{TiO}_{2}}$ and $\mathrm{TiO}_{2} / \mathrm{MWCNTs}$ NCs with Varying Composition of MWCNTs

\begin{tabular}{|c|c|c|c|c|c|c|}
\hline \multirow[b]{2}{*}{ Rietveld refinement factors } & \multicolumn{6}{|c|}{ samples } \\
\hline & $\mathrm{TiO}_{2}(\mathrm{~T})$ & T@0.01 C & $\mathrm{T} @ 0.05 \mathrm{C}$ & T@0.10 C & $\mathrm{T} @ 0.25 \mathrm{C}$ & T@1.00 C \\
\hline$\chi^{2}$ & 1.53 & 1.59 & 1.24 & 1.26 & 1.60 & 1.48 \\
\hline$R_{\mathrm{B}}(\%)$ & 3.65 & 4.15 & 1.74 & 4.62 & 4.06 & 3.20 \\
\hline$R_{\mathrm{F}}(\%)$ & 3.43 & 4.69 & 1.72 & 3.60 & 4.09 & 4.62 \\
\hline$R_{\mathrm{wp}}$ & 29.8 & 34.4 & 26.12 & 34.2 & 33.5 & 22.1 \\
\hline$R_{\text {exp }}$ & 24.1 & 27.2 & 21.13 & 27.1 & 26.4 & 18.1 \\
\hline$D(\mathrm{~nm})$ & 17 & 18 & 20 & 21 & 22 & 24 \\
\hline$a=b(\AA)$ & 3.7880 & 3.7878 & 3.7874 & 3.7854 & 3.7851 & 3.7871 \\
\hline$c(\AA)$ & 9.5025 & 9.5178 & 9.5191 & 9.5097 & 9.5096 & 9.5198 \\
\hline$V\left(\AA^{3}\right)$ & 136.35 & 136.55 & 136.54 & 136.21 & 136.20 & 136.51 \\
\hline$\rho\left(\mathrm{g} / \mathrm{cm}^{3}\right)$ & 4.554 & 4.488 & 4.505 & 4.273 & 4.338 & 4.475 \\
\hline O position $(\mathrm{z})$ & 0.2004 & 0.2005 & 0.1993 & 0.2033 & 0.1993 & 0.2003 \\
\hline
\end{tabular}

and $19 \mathrm{~nm}$. The structural cell parameters of the samples are calculated and presented (Table S1, SI). The expected peak position at 26.17 (002) reflection for MWCNTs did not appear in the $\mathrm{TiO}_{2} /$ MWCNTs NCs because of either a tiny amount present in the composition or shielding by the most intense peak of anatase $\mathrm{TiO}_{2}$ appearing at $\sim 25.21(101){ }^{23}$ As the content of MWCNTs increases in composite, a small change is observed in the peak positions with a definitive increase in the intensity of characteristic peaks of $\mathrm{TiO}_{2}$. The change in the peak positions of samples is reflected through the various cell parameters, crystallite size, and lattice strain, ${ }^{24}$ while the shifts in the intensity of the peaks are justified through the lattice sites of ions present in the $\mathrm{TiO}_{2}$ lattice (Table S1, SI). ${ }^{25}$

The quantitative studies related to structural properties were further confirmed by the Rietveld refinement method using the Fullprof 2000 software package. Rietveld refined XRD patterns of the bare $\mathrm{TiO}_{2} \mathrm{NPs}$ and $\mathrm{T} @ 0.1 \mathrm{C}$ NCs are shown in Figure $2(\mathrm{a}, \mathrm{b})$, and the remaining patterns are also shown in the Supporting Information (Figures S3, S4, S5, and S6, SI).

The lattice reflections such as (101), (004), (112), (200), (202), (105), (211), (204), (116), (220), and (215) in the Rietveld refined XRD patterns confirm the formation of the tetragonal anatase crystal structure. In the refinement, the oxygen positions $(x, y, z)$ have been considered as free parameters, and fractional atomic positions have been taken as fixed. Other parameters such as lattice, temperature, occupancies, scale factors, and shape parameters have also been considered as free parameters. The quality of the Rietveld refinement quantified by the corresponding figures of merit, viz., $R_{\mathrm{wp}}$, the goodness of fit $\left(\chi^{2}\right)$, and pseudo-Voigt function, corrected the background of the pattern.

The atomic coordinates and occupancies of different atoms of the different samples are also presented (Table S2, SI). In the entire refined patterns, the value of "goodness of fit $\left(\chi^{2}\right)$ " lies in the range of $1-1.5$; this indicates well the extent of fitting. (The Rietveld refined factors such as $\chi^{2}, R_{\mathrm{wp}}, R_{\text {exp }}, R_{\mathrm{B}}$, $R_{\mathrm{F}}$, etc. of all samples are summarized in Table 1.) The values of the various $R$ factors are slightly higher, which may be due to the nanocrystalline nature of the samples and also could be assigned to the larger signal-to-noise ratio. ${ }^{26}$ Based on these Rietveld refinements, the average crystallite sizes $(D)$ have been calculated using the Scherrer formula, which is observed from 17 to $24 \mathrm{~nm}$. The increase in crystallite size, as well as little change related to lattice parameters of the samples, is observed with increasing composition of MWCNTs in the $\mathrm{TiO}_{2}$ host lattice.

Raman spectra of the bare $\mathrm{TiO}_{2}$ NPs, MWCNTs only, and representative T@0.1 C NCs are shown in Figure 3(a). Raman spectrum of $\mathrm{TiO}_{2} \mathrm{NPs}$ shows the characteristic peaks at 144.69, $398.4,516.78$, and $640.92 \mathrm{~cm}^{-1}$ corresponding to the $\mathrm{E}_{\mathrm{g}}(1)$, $B_{1 g}, A_{1 g}$, and $E_{g}(2)$ modes of vibrations, respectively. 



Figure 3. Raman spectra of bare $\mathrm{TiO}_{2} \mathrm{NPs}$, $\mathrm{T} @ 0.1 \mathrm{C} \mathrm{NCs}$, and MWCNTs (inset).

These peaks confirm the presence of the anatase phase only, which is in good agreement with the XRD results. ${ }^{27}$ Raman spectrum of MWCNTs is shown in the inset, which shows two bands, namely, the D band and G band. The D band is an indicative disorder in the graphitic structure at $1346.10 \mathrm{~cm}^{-1}$ due to the disorder induced by $\mathrm{sp}^{3}$ hybridization, whereas the $\mathrm{G}$ band (characteristic ordered graphitic structure) at 1585.01 $\mathrm{cm}^{-1}$ corresponds to ordered $\mathrm{sp}^{2}$ hybridization of MWCNTs. The intensity ratio $\left(I_{\mathrm{D}} / I_{\mathrm{G}}\right)$ for the functionalized MWCNTs also reveals the presence of acidic functional moieties on the surface of MWCNTs with the conversion of the carbon atoms from $\mathrm{sp}^{2}$ to $\mathrm{sp}^{3}$ hybridization. Raman spectrum of functionalized MWCNTs with fitting results (Figure 3b) show graphitizable carbon activated by acidic functional moieties. ${ }^{28}$ Raman spectrum of a representative T@0.1 C NCs shows all the characteristic peaks of anatase $\mathrm{TiO}_{2}$ along with $\mathrm{D}(1350.96$ $\left.\mathrm{cm}^{-1}\right)$ and $\mathrm{G}\left(1582.32 \mathrm{~cm}^{-1}\right)$ bands of MWCNTs. It emphatically reveals the existence of MWCNTs composition in the NCs. ${ }^{29}$ The decrease in the peak intensity, with little shifting in the peak positions of all Raman bands for NCs, is shown in Figure 3 ( $c$ and d). It is usually due to the increase in the crystallite size with an increase in the MWCNTs content in the $\mathrm{TiO}_{2}$ host lattice.

Transmission electron microscopy (TEM), high-resolution TEM (HR-TEM) with seleced area electron diffraction (SAED) patterns of MWCNTs, bare $\mathrm{TiO}_{2}$ NPs and T@0.1 $\mathrm{C}$ NCs are shown in Figure 4 (a to i). TEM image (Figure 4(a)) of MWCNTs shows the cylindrical tubes having an average outer diameter in the range between 20 and $25 \mathrm{~nm}$ and a few micrometers in length. From HRTEM image (Figure 4(b)), the distance between the two successive inner layers of
MWCNTs is around $0.33 \mathrm{~nm}$, while the diameter between the two outermost shells is $23 \mathrm{~nm}$. SAED pattern (Figure 4(c)) shows the bright ring patterns, which correctly match to the spacing of the (002), (100), and (006) reflections. Figure 4(d,e,f) shows TEM, HRTEM, and SAED patterns of the bare $\mathrm{TiO}_{2}$ NPs. A TEM image shows the spherical nanostructures having a mean particle diameter of $15-20 \mathrm{~nm}$, while spacing for the (101) lattice fringes is $0.352 \mathrm{~nm}$. SAED pattern indicates excellent crystallinity due to a clear ring structure with lattice points that directly match the anatase phase of $\mathrm{TiO}_{2}$. Figure 4(g,h,i) shows TEM, HRTEM, and SAED patterns of representative T@0.1 C NCs. TEM image shows the spherical nanostructures of the $\mathrm{TiO}_{2} \mathrm{NPs}$ directly anchored on the surface of MWCNTs, and no bare MWCNTs is observed because of the high wall anchoring as well as density of $\mathrm{TiO}_{2}$ NPs.

HRTEM micrograph shows that the clear fringes precisely match to the spacing of the (101) reflection of $\mathrm{TiO}_{2}$ NPs. However, uncleared fringes of MWCNTs are observed in the $\mathrm{NCs}$ because, in the in situ chemical route, a stronger chemical grafting occurs at the $\mathrm{TiO}_{2} / \mathrm{MWCNT}$ interface. ${ }^{30}$ The SAED pattern of the NCs shows good ring patterns with lattice points indicating crystallinity. The indexed ring designs closely match with the spacing of the various reflections of the anatase phase.

The optical properties of NCs powders were studied through UV-visible DRS spectra. Figure 5(a) includes UV-visible DRS spectra of bare $\mathrm{TiO}_{2} \mathrm{NPs}$ and the representative $\mathrm{TiO}_{2} /$ MWCNTs NCs. All samples show the absorption edge between 382 and $400 \mathrm{~nm}$ due to the excitation of electrons from the valence band to the conduction band of the $\mathrm{TiO}_{2}$ host material. ${ }^{29}$ With the increase in MWCNTs content in $\mathrm{TiO}_{2}$, not 



Figure 4. (a,d,g) TEM images, (b,e,h) HRTEM images, and (c,f,i) SAED patterns of MWCNTs, bare TiO 2 NPs, and T@0.1 C NCs.
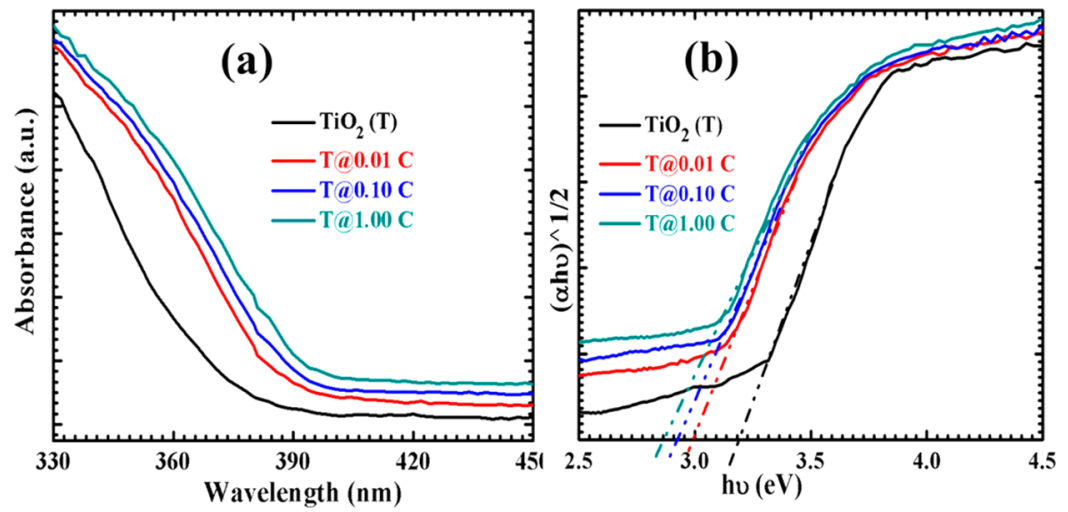

Figure 5. (a) UV-visible DRS spectra and (b) Kubelka-Munk function $(\alpha h v)^{1 / 2}$ as a function of photon energy $(h v)$ of bare TiO $\mathrm{NPs}$ and representative T@0.01 C, T@0.10 C, and T@1.00 C NCs.

only the absorption capability but also the red shifting of the absorption edge of NCs are also observed. This optical absorption behavior reveals the strong interaction between the $\mathrm{TiO}_{2}$ and MWCNTs, which results in the enhancement of surface electric charge of the $\mathrm{TiO}_{2}$ NPs by MWCNTs.
It is also beneficial for the ease of charge transfer between $\mathrm{TiO}_{2}$ and MWCNTs and hence results in the enhancement of light absorption capability of $\mathrm{TiO}_{2}$ in the visible region, which are excellent aspects for light-harvesting ability of the photoanode material. ${ }^{31}$ To know the impact of varying content of MWCNTs on the optical properties of $\mathrm{TiO}_{2}$, the optical 
energy band gaps of all samples were determined. Optical energy band gaps of all the representative samples were calculated by using the Kubelka-Munk function $(\alpha h v)^{1 / 2}$ (where $\alpha$ is the absorption coefficient) as a function of photon energy $(h v)$, which is shown in Figure 5(b). The optical energy band gap is recognized by plotting the intercept tangent to the $x$-axis in a graph, decreased from 3.2 to $2.85 \mathrm{eV}$ with an increase in the content of MWCNTs in $\mathrm{TiO}_{2}$ (Table 2) (Figure S7, SI). The calculated optical band gap is firm evidence for the visiblelight absorption by NCs as compared to bare $\mathrm{TiO}_{2} \mathrm{NPs}$.

Table 2. Optical Energy Band Gap, BET Surface Area, Amount of Dye Adsorbed (N719 and RuPc) on the Surface of the Bare $\mathrm{TiO}_{2}$, and Representative NCs Samples

\begin{tabular}{ccccc} 
& & & \multicolumn{2}{c}{$\begin{array}{c}\text { amount of dye adsorbed } \\
\left(\mathrm{mol} / \mathrm{cm}^{2}\right)\end{array}$} \\
\cline { 3 - 5 } samples & $\begin{array}{c}\text { optical band } \\
\text { gap }(\mathrm{eV})\end{array}$ & $\begin{array}{c}\text { surface area } \\
\left(\mathrm{m}^{2} / \mathrm{g}\right)\end{array}$ & $\mathrm{N} 719$ & $\mathrm{RuPc}$ \\
$\mathrm{TiO}_{2}(\mathrm{~T})$ & 3.20 & 90.27 & $3.00 \times 10^{-5}$ & $1.03 \times 10^{-5}$ \\
$\mathrm{~T} @ 0.1 \mathrm{C}$ & 2.90 & 109.85 & $3.23 \times 10^{-5}$ & $1.15 \times 10^{-5}$ \\
$\mathrm{~T} @ 1.0 \mathrm{C}$ & 2.85 & 60.42 & $2.47 \times 10^{-5}$ & -- \\
\hline
\end{tabular}

To study the electronic behavior as well as separation of photogenerated charge carrier trapping with the fate of excitons in the semiconductor materials, the photoluminescence (PL) studies of the various materials were investigated. The PL spectra of bare $\mathrm{TiO}_{2} \mathrm{NPs}$ and $\mathrm{TiO}_{2} /$ MWCNTs NCs in the wavelength range between 450 and $650 \mathrm{~nm}$ are presented in Figure 6.

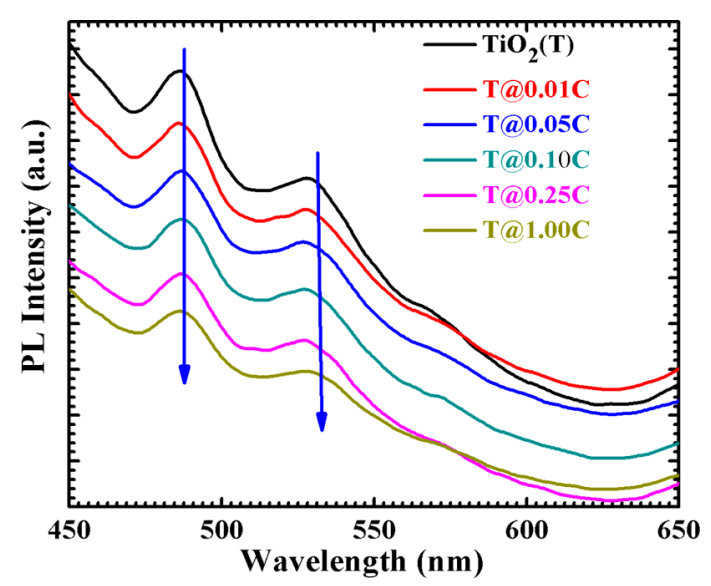

Figure 6. Photoluminescence emission spectra of bare $\mathrm{TiO}_{2} \mathrm{NPs}$ and $\mathrm{TiO}_{2} /$ MWCNTs NCs with varying content of MWCNTs.

The emission peaks appeared at 486 and $527 \mathrm{~nm}$, corresponding to the band-band emission and metalnonmetal charge transfer transitions by excitation wavelength at $365 \mathrm{~nm}$ (Figure S8, SI). ${ }^{32}$ With the increase in the content of MWCNTs, the PL intensity of the respective emission peaks decreases. The decreasing behavior of PL is attributed to reductions in the radiative recombination of photoinduced electrons trapped at the surface of $\mathrm{TiO}_{2}$ with the content of MWCNTs, and hence NCs are best for the efficient charge separations. The detailed charge separation and energy level diagram of the photoelectrode are shown in the Supporting Information (Scheme S1, SI).

FT-IR spectra of MWCNTs, bare $\mathrm{TiO}_{2}$ NPs, and representative NCs are shown in Figure 7. FT-IR spectrum

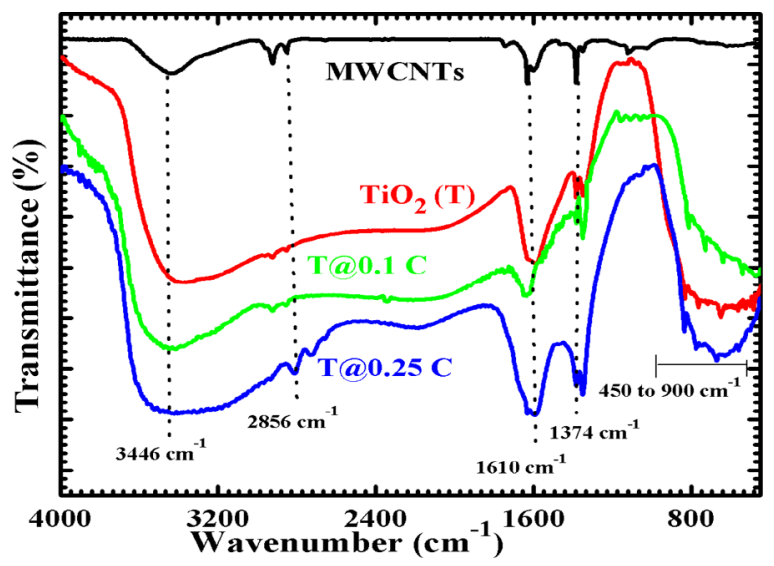

Figure 7. FT-IR spectra of MWCNTs, bare $\mathrm{TiO}_{2} \mathrm{NPs}$, and representative T@0.1 C and T@0.25 C NCs.

of MWCNTs shows the peaks at 3440, 2925, 2845, 1740, 1632, 1383 , and $1110 \mathrm{~cm}^{-1}$ corresponding to the $\mathrm{O}-\mathrm{H}$ stretching vibration, $\mathrm{C}-\mathrm{H}$ stretching, $\mathrm{C}-\mathrm{OH}$ stretching, $\mathrm{C}=\mathrm{O}$ stretching, $\mathrm{O}-\mathrm{H}$ deformation vibrations, and alkoxy $\mathrm{C}-\mathrm{O}$ stretching vibrations, respectively. ${ }^{33,34}$

FT-IR spectra of $\mathrm{TiO}_{2}$ NPs or NCs show the broad absorption band from 3000 to $3400 \mathrm{~cm}^{-1}$ assigned to the $-\mathrm{OH}$ stretching frequency vibration. The bands at the region 3000$3400 \mathrm{~cm}^{-1}$ broaden, with the content of MWCNTs, reflecting the increase in surface hydroxylation of NCs. A band in the range of $2925-2856 \mathrm{~cm}^{-1}$, analogous to the $\mathrm{Ti}-\mathrm{OH}$ stretching vibration, is shifted to the lower frequency region at 2820$2730 \mathrm{~cm}^{-1}$ in the $\mathrm{TiO}_{2} /$ MWCNTs NCs. The shifting is due to the $-\mathrm{OH}$ stretching frequency region of the $\mathrm{Ti}$ precursor overlapping with the other contributions like $\mathrm{C}=\mathrm{O}, \mathrm{C}-\mathrm{O}$, and $\mathrm{O}-\mathrm{C}=\mathrm{O}$ moieties of MWCNTs. ${ }^{23}$ Similarly, other peaks at $1374 \mathrm{~cm}^{-1}$ and $1590-1630 \mathrm{~cm}^{-1}$ in the NCs are also shifted to the longer frequency region, which reveals the interaction between the carboxylate groups of MWCNTs with the Ti precursors. ${ }^{30}$ The $\mathrm{TiO}_{2}$ NPs or NCs samples show the broad peak in the range between 550 and $900 \mathrm{~cm}^{-1}$, due to the various stretching vibrations such as $\mathrm{Ti}-\mathrm{O}, \mathrm{O}-\mathrm{Ti}-\mathrm{O}, \mathrm{Ti}-\mathrm{O}-$ $\mathrm{C}$, and $\mathrm{Ti}-\mathrm{O}-\mathrm{C}=\mathrm{O}^{35}$

The chemical composition and the chemical states on the surface of the elements are studied by using EDAX, which is illustrated in the Supporting Information (Figure S2, SI) and XPS analysis shown in Figure 8. Figure 8(a) shows the highresolution core level spectrum of the $\mathrm{Ti}$ ion, and it consists of two peaks at 458.95 and $464.66 \mathrm{eV}$ corresponding to $\mathrm{Ti} 2 \mathrm{P}_{3 / 2}$ and $\mathrm{Ti} 2 \mathrm{P}_{1 / 2}$ states, respectively. The difference in binding energy between the two peaks $(5.69 \mathrm{eV})$ corresponds to the $\mathrm{Ti}^{4+}$ state in the octahedral environment of the anatase $\mathrm{TiO}_{2}{ }^{36}$ Figure $8(\mathrm{~b})$ shows the high-resolution core-level XPS spectrum of oxygen species. A major peak at $530.9 \mathrm{eV}$ is due to the presence of lattice oxygen in the sample and is deconvoluted into two peaks at 531.4 and $532.6 \mathrm{eV}$ and analogous to the carbonyl $(-\mathrm{C}=\mathrm{O})$ or carboxylic species from the $\mathrm{TiO}_{2} /$ MWCNTs NC. ${ }^{29}$ The high-resolution C 1 s core-level spectrum of the same sample is shown in Figure 8(c). A major peak at $284.8 \mathrm{eV}$ is due to the $\mathrm{sp}^{2}$-hybridized carbon atoms, and it also deconvoluted into four peaks at 284.85, 285.26, 285.57, and $289.28 \mathrm{eV}$ corresponding to the $\mathrm{sp}^{2}$-bonded carbon atoms of $\mathrm{C}=\mathrm{C}, \mathrm{C}-\mathrm{O}, \mathrm{C}=\mathrm{O}$, and ester groups $(\mathrm{O}-\mathrm{C}=\mathrm{O})$, respectively. The existence of all these groups is beneficial for making the chemical bond formation between the $\mathrm{TiO}_{2}$ lattice and 

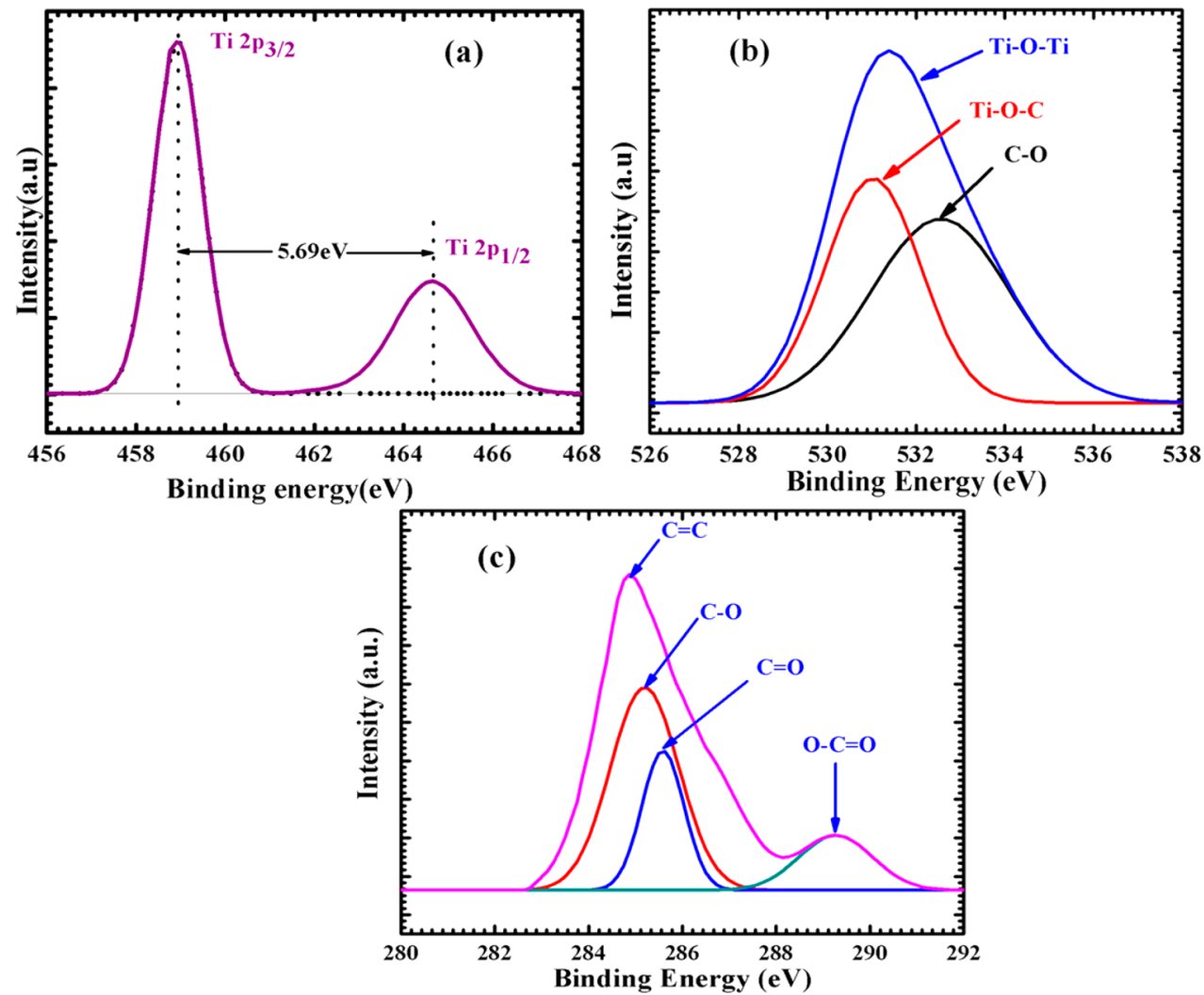

Figure 8. High-resolution XPS spectra of (a) Ti 2p, (b) C 1s, and (c) O 1s core-level spectra of T@0.1 C NCs powder.

MWCNTs, and the absence of the other peak at $281 \mathrm{eV}$ indicates that elemental carbon is not doped in the $\mathrm{TiO}_{2}$ lattice. $^{37}$

Brunauer-Emmett-Teller (BET) analysis gives the specific surface area of the materials. Figure 9 shows the nitrogen $\left(\mathrm{N}_{2}\right)$

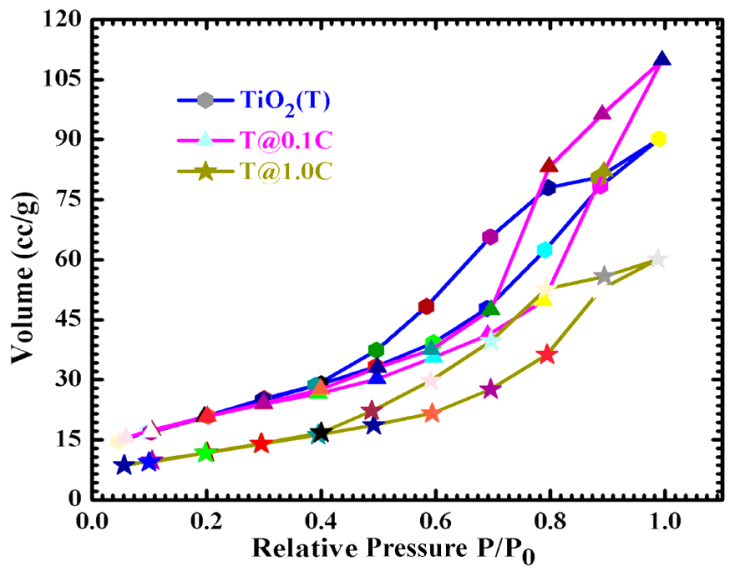

Figure 9. $\mathrm{N}_{2}$ adsorption isotherms of bare $\mathrm{TiO}_{2} \quad \mathrm{NPs}$ and representative T@0.1 C and T@1.0 C NCs.

adsorption-desorption isotherms of bare $\mathrm{TiO}_{2} \mathrm{NPs}$, representative T@0.1 C, and T@1.0 C NCs. The separation between the $\mathrm{N}_{2}$ adsorption-desorption curves indicates that samples exhibit type IV isotherms. ${ }^{38} \mathrm{~T} @ 0.1 \mathrm{C}$ NCs as well as bare $\mathrm{TiO}_{2}$ show that the $\mathrm{N}_{2}$ adsorption rises abruptly due to the capillary condensation of $\mathrm{N}_{2}$ and leading to the formation of type $\mathrm{H} 1$ hysteresis loops. It also signifies the particles with spherical pore geometry and a high degree of pore size uniformity, while in the case of T@1.0 C NCs, the decrease in $\mathrm{N}_{2}$ adsorption is observed due to the reduction in surface area and also improper anchoring of $\mathrm{TiO}_{2} \mathrm{NPs}$ on the surface of MWCNTs. ${ }^{39}$ The BET parameters of the samples are summarized in Table 2.

The specific surface area of bare $\mathrm{TiO}_{2}$ is found to be 90.27 $\mathrm{m}^{2} / \mathrm{g}$, which is intermediate between the surface area of T@0.1 C $\left(109.85 \mathrm{~m}^{2} / \mathrm{g}\right)$ and T@1.0 C $\left(60.42 \mathrm{~m}^{2} / \mathrm{g}\right)$ samples. Overall, it reveals that the least addition of MWCNTs in the NCs increases the surface area to the $\mathrm{TiO}_{2}$ matrix due to the proper anchoring of $\mathrm{TiO}_{2}$ on the surface of the MWCNTs. ${ }^{40}$ In the design of the photoelectrode, the N719 dye is directly anchored on the surface of the NCs thin films through carboxylic groups of the N719 dye. ${ }^{41}$ However, due to the absence of carboxylic groups, RuPc is not directly anchored to the surface of the NCs thin films. Therefore, isonicotinic acid (INA) is used as a bridging ligand to connect RuPc with the surface of the NCs thin films, and hence the overall connectivity of RuPc with NCs through INA is similar to that of N719 dye. The bridging role of INA is confirmed by measuring the absorption spectra of $\mathrm{TiO}_{2} /$ MWCNTs with and without INA, which is shown in the Supporting Information (Figure S9, SI). In comparison, the optical absorption of the $\mathrm{TiO}_{2} / \mathrm{MWCNTs} / \mathrm{INA} / \mathrm{RuPc}$ photoelectrode is higher than that without INA $\left(\mathrm{TiO}_{2} / \mathrm{MWCNTs} /\right.$ $\mathrm{RuPc})$. The optical behavior powerfully reveals that INA binds steadily to both dye and host materials, viz., the dye molecule through the pyridine ring and $\mathrm{TiO}_{2}$ /MWCNTs through carboxylic acid moieties (Scheme 1).

After anchoring with dyes, the photoanodes further characterized by using UV-visible absorption spectroscopy. The UV-visible absorption spectrum of the $\mathrm{TiO}_{2}$-MWCNTs/ N719 photoelectrode shows two characteristics absorption bands of N719 in the range 310-600 nm (Figure 10). The first 
Scheme 1. Schematic Representation of the Sandwich Structure of DSSCs Having either Dye (a) N719 or (b) RuPc Anchored Nanocrystalline $\mathrm{TiO}_{2} / \mathrm{MWCNT}$ Composites as a Working Electrode and Pt/ITO as the Counter Electrode along with the Redox Mediator
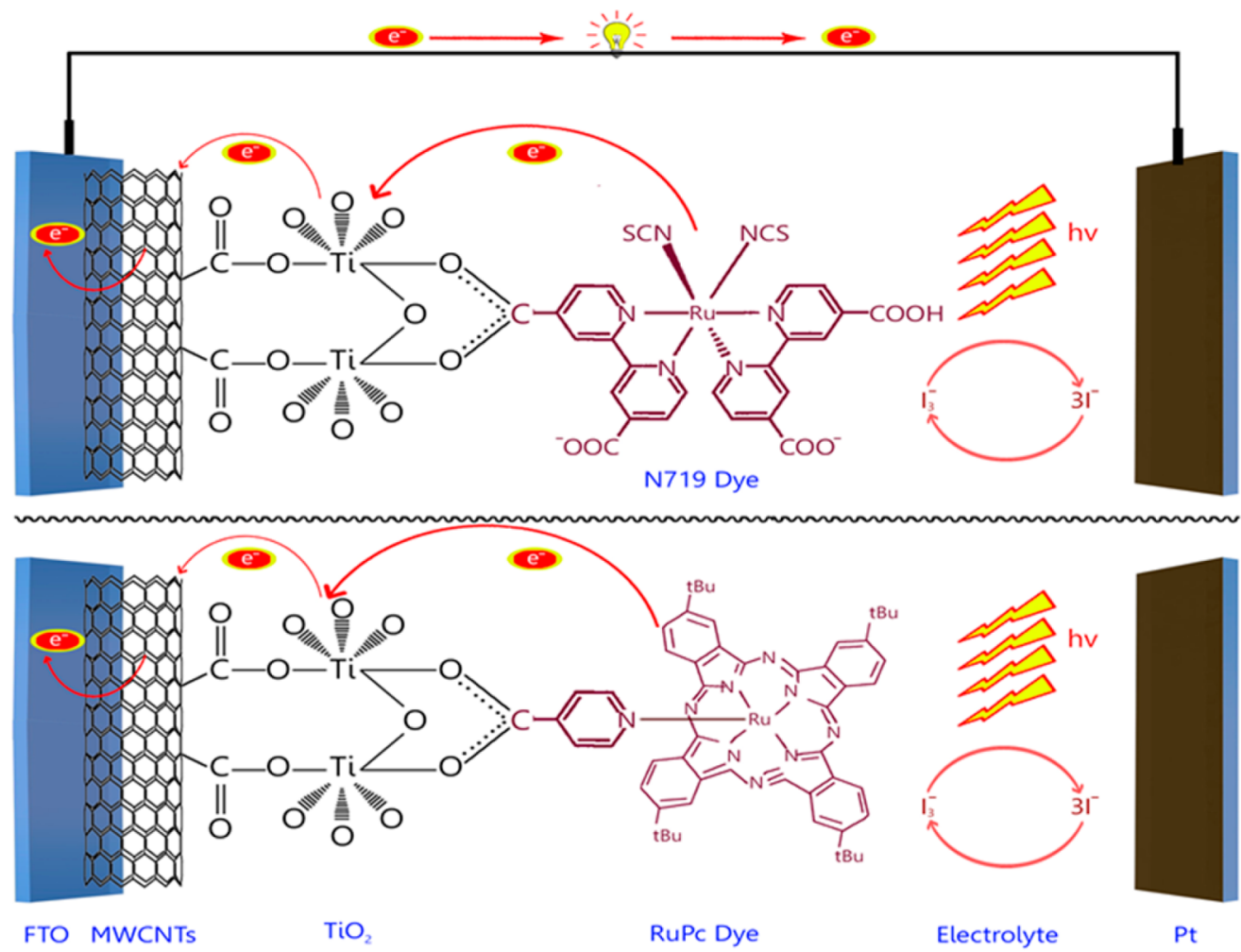

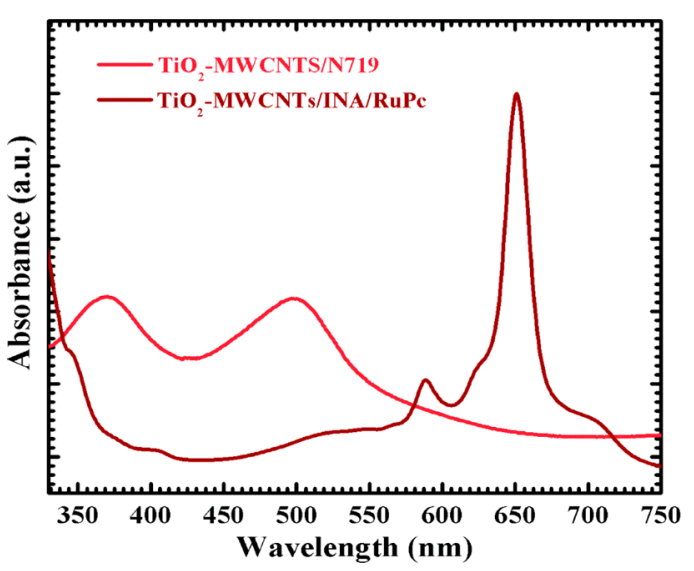

Figure 10. UV-visible absorption spectra of $\mathrm{TiO}_{2} / \mathrm{MWCNTs} / \mathrm{N} 719$ and $\mathrm{TiO}_{2} /$ MWCNTs/INA/RuPc based photoanodes.

band appeared at $370 \mathrm{~nm}$ due to the $\pi-\pi^{*}$ transition of the aromatic rings, and the second band is at $502 \mathrm{~nm}$ due to the internal charge transfer transition. ${ }^{42}$ Similarly, the $\mathrm{TiO}_{2} /$ MWCNTs/INA/RuPc photoanode shows the characteristic Q-band of RuPc at $650 \mathrm{~nm}$, where the maximum solar photons occur. ${ }^{43}$ In addition to the Q-band, it also absorbs the light to a small extent at the various regions of the electromagnetic spectrum. The bands in UV-visible patterns are characteristic absorptions of individual ingredients present in the photoelectrodes.

After that, the amount of N719 and RuPc dyes was loaded on the surface of the NCs thin films measured by desorbing a 1.0 $\mathrm{cm}^{2}$ area of the dye adsorbed thin films into the $5 \mathrm{~mL}$ aqueous $1 \mathrm{mM} \mathrm{KOH}$ solution. It is evident from Figure 11(a) that the absorption spectra of N719 dye were detached from the $\mathrm{TiO}_{2}$ $\mathrm{NPs}$ and representative NCs thin films. It shows the two distinct absorption maxima at 370 and $500 \mathrm{~nm}$, but the actual N719 dye shows maximum absorption peaks at 380 and 518 $\mathrm{nm}$. The shifting to the 370 and $500 \mathrm{~nm}$ is due to the anchoring of the N719 dye molecules on the surface of the NCs thin films. ${ }^{42}$ RuPc shows the absorption maxima at $650 \mathrm{~nm}$ [Figure $11(\mathrm{~b})]$ due to the characteristic Q-band. The quantification of dye adsorbed on the thin-film surface is calculated from Figure 11( $\mathrm{a}$ and $\mathrm{b}$ ) and illustrated in Table 2. The observed result shows the T@0.1 C NCs photoelectrode having the maximum dye adsorption capability as compared to the bare $\mathrm{TiO}_{2} \mathrm{NPs}$ and other NCs thin films. It is fascinating that the dye loading capacity of T@0.1 C NCs is higher as compared to the bare $\mathrm{TiO}_{2}$ NPs and other NCs based photoelectrodes. Hence, the high loading of dye offers the better harvesting of photons in the visible range of dyes and will increase the photocurrent density $\left(J_{\text {sc }}\right)$ of the devices.

The sensitized photoanodes were used for sandwich-type DSSCs (Scheme S1, SI) and further tested for photovoltaic performance using a solar simulator under standard AM 1.5 one sun illumination $\left(100 \mathrm{~mW} / \mathrm{cm}^{2}\right)$ with an active area of 0.25 $\mathrm{cm}^{2}$. In addition to the assessment of the sensitizer's impact, the effect of MWCNTs on the photovoltaic properties of the $\mathrm{TiO}_{2}$ host lattice with the N719-based DSSC device showed different solar cell parameters. Figure $12(\mathrm{a}, \mathrm{b})$ shows the current density-voltage characteristic curves of the samples with N719 and RuPc dyes, respectively.

The different photovoltaic parameters such as photocurrent density $\left(J_{\mathrm{sc}}\right)$, open-circuit voltage $\left(V_{\mathrm{oc}}\right)$, fill factor $(\mathrm{FF})$, and light to electrical conversion efficiency $(\eta)$ of the DSSCs are represented in Table 3. 

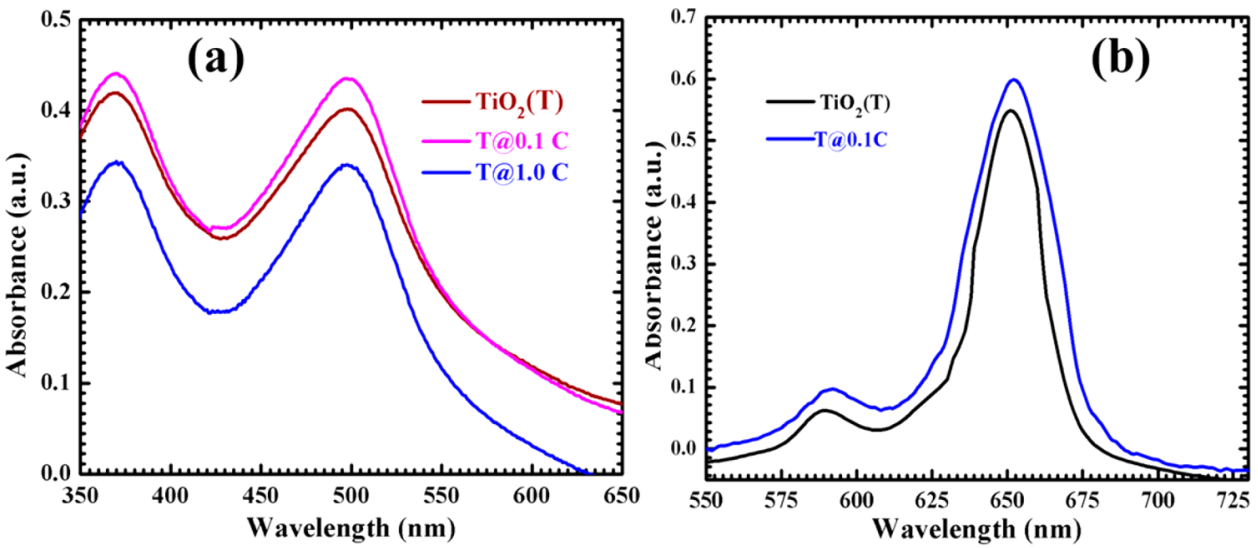

Figure 11. UV-vis absorption spectra of solutions containing (a) N719 and (b) RuPc dyes detached from bare $\mathrm{TiO}_{2}$ and representative $\mathrm{NCs}_{\text {thin }}$ films (all with $1.0 \mathrm{~cm}^{2}$ area) in $5 \mathrm{~mL}$ of aqueous solution of $1 \mathrm{mM} \mathrm{KOH}$.


Figure 12. Photocurrent density vs voltage curves of (a) bare $\mathrm{TiO}_{2}$ and $\mathrm{TiO}_{2} / \mathrm{MWCNTs} \mathrm{NCs}$ with varying composition of MWCNTs for N719 and (b) bare $\mathrm{TiO}_{2}$ and $\mathrm{T} @ 0.1 \mathrm{C}$ NCs for RuPc-based DSSC devices.

Table 3. Photovoltaic Parameters of Bare $\mathrm{TiO}_{2}$ NPs and $\mathrm{TiO}_{2}$ /MWCNTs NCs with N719- and RuPc-Based DSSC Devices

\begin{tabular}{|c|c|c|c|c|c|}
\hline \multirow[b]{2}{*}{ samples } & \multirow[b]{2}{*}{$\begin{array}{c}\text { MWCNT } \\
\text { content (wt \%) }\end{array}$} & \multicolumn{4}{|c|}{ solar cell parameters } \\
\hline & & $\begin{array}{c}J_{\mathrm{SC}} \\
\left.(\mathrm{mA} \mathrm{cm})^{-2}\right)\end{array}$ & $\begin{array}{l}V_{\mathrm{OC}} \\
(\mathrm{V})\end{array}$ & $\mathrm{FF}(\%)$ & $\eta(\%)$ \\
\hline \multicolumn{6}{|c|}{ For N719 Dye } \\
\hline $\mathrm{TiO}_{2}(\mathrm{~T})$ & 0.00 & 07.37 & 0.330 & 43.77 & 1.04 \\
\hline $\mathrm{T} @ 0.01 \mathrm{C}$ & 0.01 & 14.27 & 0.560 & 49.48 & 3.95 \\
\hline T@0.05 C & 0.05 & 15.50 & 0.560 & 51.72 & 4.49 \\
\hline T@0.1 C & 0.10 & 17.60 & 0.630 & 56.08 & 6.21 \\
\hline T@0.25 C & 0.25 & 12.64 & 0.540 & 44.61 & 3.04 \\
\hline T@1.0 C & 1.00 & 11.24 & 0.530 & 50.21 & 2.99 \\
\hline \multicolumn{6}{|c|}{ For RuPc Dye } \\
\hline Bare $\mathrm{TiO}_{2}$ & 0.00 & 0.46 & 0.300 & 57.49 & 0.07 \\
\hline T@0.1 C & 0.10 & 6.73 & 0.580 & 53.24 & 2.07 \\
\hline
\end{tabular}

In the case of $\mathrm{FTO} / \mathrm{TiO}_{2}-\mathrm{MWCNTs} / \mathrm{N} 719$ DSSCs, the overall highest power conversion efficiency of $6.21 \%$ is noted for T@0.1 C NC-based DSSCs. This highest efficiency of T@ $0.1 \mathrm{C}$ NC-based DSSCs is also reflected through its highest values of $J_{\mathrm{sc}}\left(17.60 \mathrm{~mA} / \mathrm{cm}^{2}\right), V_{\mathrm{oc}}(0.630 \mathrm{~V})$, and FF $(56.08 \%)$. However, the $J_{\mathrm{sc}}$ value of other NC-based DSSCs varied from 11.24 to $15.50 \mathrm{~mA} / \mathrm{cm}^{2}$ (Figure $13(\mathrm{~b})$ ). Specifically, the $J_{\mathrm{sc}}$ value is increased up to T@0.1 C NC-based DSSCs, and after that, it decreased to $11.24 \mathrm{~mA} / \mathrm{cm}^{2}$ for $\mathrm{T} @ 1.0 \mathrm{C} \mathrm{NC}$-based DSSCs, which is shown in Table 3. It is also interesting that the
$J_{\text {sc }}$ value of NC-based DSSCs is higher than that of bare $\mathrm{TiO}_{2}$ based DSSCs. This change in $J_{s c}$ value of NCs or bare $\mathrm{TiO}_{2}-$ based DSSCs is collinear with the change in surface area of NCs as well as dye loading capacity of NC-based photoelectrodes (Table 2). In addition, the $J_{\mathrm{sc}}$ value of $\mathrm{TiO}_{2} /$ MWCNTs/N719 DSSCs is higher than that of $\mathrm{TiO}_{2} / \mathrm{MWCNTs} / \mathrm{RuPc}$ DSSCs; this is attributed to the reasons such as connectivity between the host material and dye and coverage of optical region. In the case of N719-based DSSCs, the direct connectivity between N719 and $\mathrm{TiO}_{2}$ /MWCNTs is observed, while in RuPc-based DSSCs the INA acts as a bridging ligand between $\mathrm{TiO}_{2} /$ MWCNTs and dye. Though absorption is higher for RuPc dye, the coverage region is small. Hence, the synergetic effect of these factors is responsible for an improved charge-carrier transport resulting in an increase in $J_{\mathrm{sc}}$ values of $\mathrm{TiO}_{2} /$ MWCNTs/N719-based DSSCs. ${ }^{44}$

A plot of $V_{\text {oc }}$ as a function of MWCNTs composition in $\mathrm{TiO}_{2}$ is shown in Figure 13(c). It revealed that no significant change is observed for $V_{\text {oc }}$ value in NC-based DSSCs except T@0.1 C NC-based DSSCs. The $V_{\text {oc }}$ value of NC-based DSSCs is seen around $0.550 \mathrm{~V}$, which is still lower than that for bare $\mathrm{TiO}_{2}$ based DSSCs. The lower photovoltage is attributed to the nearly same absorption edge of the NC photoelectrodes, while in the case of FF value the change is similar to that of $J_{\mathrm{sc}}$ as well as the efficiency of DSSCs. Up to T@0.1 C NC-based DSSCs, the $\mathrm{FF}$ value increased to $56 \%$ from $43 \%$, and after that, it decreased for higher content of MWCNTs in the $\mathrm{TiO}_{2}$ host lattice, which is shown in Figure 13(d). Moreover, the 



Figure 13. Plot of MWCNTs content (wt \%) in the $\mathrm{TiO}_{2}$ host lattice as a function of (a) $\eta$, (b) $J_{\mathrm{sc}}$ (c) $V_{\mathrm{oc}}$ and (d) FF. [Conditions: substrate: FTO, dye: $0.3 \mathrm{mM} \mathrm{N719}$ in 1:1 ratio of tertbutyl alcohol and acetonitrile, electrolyte: $1.0 \mathrm{M} \mathrm{LiI}+0.06 \mathrm{M} \mathrm{I}_{2}$ in propylene carbonate, area: $0.25 \mathrm{~cm}^{2}$, counter: Pt-deposited ITO, light source: $300 \mathrm{~W}$ xenon lamp with AM 1.5G filter.]

efficiency of all NCs-based DSSCs is in the range of 2.99$6.21 \%$, which is three to six times more than that of bare $\mathrm{TiO}_{2}-$ based DSSCs (1.04\%) [Figure 12(a)]. From the photovoltaic analysis of $\mathrm{TiO}_{2} /$ MWCNTs NCs with N719 dye sensitization, it is concluded that the highest solar to electrical conversion efficiency is observed for T@0.1 C NCs-based DSSCs, and hence, for further photovoltaic studies with RuPc dye, only the T@0.1 C NCs-based photoelectrode is used. In the case of RuPc, T@0.1 C NC-based DSSCs result in a power conversion efficiency of $2.07 \%$. The other photovoltaic parameters of T@ $0.1 \mathrm{C} \mathrm{NC}$-based DSSCs are $J_{\mathrm{sc}}\left(6.73 \mathrm{~mA} / \mathrm{cm}^{2}\right), V_{\text {oc }}(0.580 \mathrm{~V})$, and FF (53.24\%). Overall, the power conversion efficiency of the $\mathrm{TiO}_{2}$-based DSSC device is low as compared to the $\mathrm{TiO}_{2} /$ MWCNTs NC-based DSSC device. In DSSCs, the excited electrons (LUMO) from the dye are injected into the conduction band (LUMO) of $\mathrm{TiO}_{2}$ and finally transferred into the counter electrode through two ways, namely, electric field driven charge transport ${ }^{45}$ and a trap-limited diffusion process. ${ }^{46}$ However, in bare $\mathrm{TiO}_{2}$ the electron transport is negligible because the diffusion of electrons through the $\mathrm{TiO}_{2}$ network undergoes different interfaces, and these interfaces act as electron trap centers, and hence there is a possibile electron-hole pair recombination. ${ }^{47}$ However, in $\mathrm{TiO}_{2} /$ MWCNTs NCs-based DSSC device the MWCNTs acts as a carrier transporter with proper channels, and hence it avoids the possibility of recombination; that is, it minimizes the charge transport resistance of the device. Once the excited electron from the dye is injected into the semiconductor, it has an efficient pathway to reach the counter electrode through
MWCNTs, and hence it greatly enhances the photoresponse of the cell. ${ }^{48}$

In the end, with varying sensitizers, the photovoltaic performance of T@0.1 C NCs-based DSSCs is significantly higher. The power conversion efficiency of T@0.1 C NCs/ N719 DSSCs is almost three times more than that of RuPcbased DSSCs, and hence the overall efficiency reaches $6.21 \%$ from either $1.04 \%$ of bare $\mathrm{TiO}_{2}$ with $\mathrm{N} 719$ or $0.07 \%$ of bare $\mathrm{TiO}_{2}$ with RuPc. It is interesting that although there is a resemblance in the connection of dyes with the surfaces of $\mathrm{TiO}_{2}$-MWCNTs the conversion efficiency of DSSCs with different dyes is different due to their optical absorption coverge. Overall, the energy conversion efficiency of T@0.1 C NCs/N719 DSSCs is higher than others ( $\mathrm{T} @ 0.1 \mathrm{C} \mathrm{NCs/RuPc}$, $\mathrm{TiO}_{2} / \mathrm{N} 719$, and $\mathrm{TiO}_{2} / \mathrm{RuPc}$ DSSCs). Along with the surface area of the host material, the higher efficiency is corelated to the well coverage of the electromagnetic spectrum by N719-based DSSCs, resulting in more absorption of light with the formation of efficient charge carriers, which is responsible for the significant enhancement of the conversion efficiency. The detailed absorption edge and absorption strength of the two different sensitizer-based DSSCs is discussed in the incident photon-to-charge carrier conversion efficiency (IPCE) measurement.

The photovoltaic performances of the N719 and RuPc-based DSSC devices are confirmed by using IPCE at different incident wavelengths and determined by using the following relation 

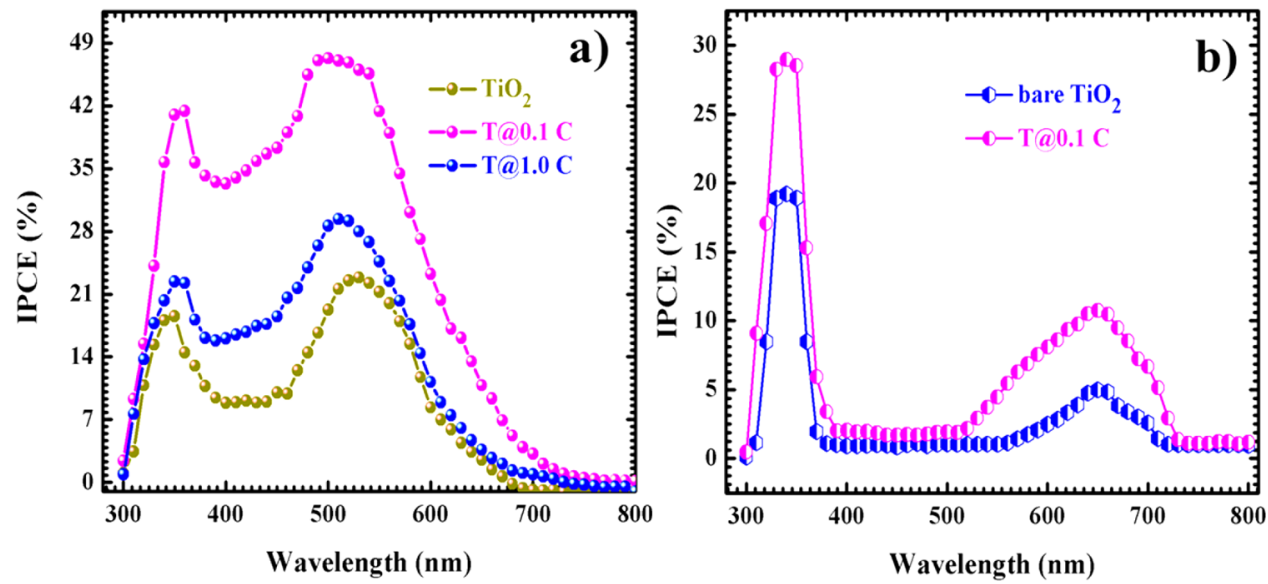

Figure 14. IPCE spectra of bare $\mathrm{TiO}_{2}$ NPs and representative NCs for (a) N719 and (b) RuPc-based DSSCs.

$$
\operatorname{IPCE}(\%)=\frac{\left[1240 \times J_{\mathrm{sc}}\left(\frac{\mathrm{A}}{\mathrm{cm}^{2}}\right)\right]}{\left[\lambda(\mathrm{nm}) \times I_{\text {inc }}\left(\frac{\mathrm{w}}{\mathrm{cm}^{2}}\right)\right]} \times 100
$$

where $J_{\mathrm{sc}}$ is the short-circuit current density: $\lambda$ is the wavelength of the incident light; and $I_{\text {inc }}$ is the power of the incident light. ${ }^{49}$ Figure 14(a, b) shows the IPCE spectra for the N719- and RuPc-based DSSCs, respectively. In the case of an N719 dye, the photocurrents for all $\mathrm{TiO}_{2}-\mathrm{MWCNT} \mathrm{NC}$-based DSSCs are generated in the range from 300 to $650 \mathrm{~nm}$. The two distinct regions (viz., $300-400 \mathrm{~nm}$ and $475-650 \mathrm{~nm}$ ) are observed for current generations.

The former region is found due to the characteristic absorption of $\mathrm{TiO}_{2}$ as well as the small extent of N719 dye, while the latter is due to the high absorption of the N719 dye. ${ }^{23}$ The maximum IPCE value of $\mathrm{TiO}_{2} /$ MWCNTs NC-based DSSCs reached 47\% for T@0.1 C NCs/N719-based DSSCs as compared to others, which is also in good agreement with the observed maximum $J_{\text {sc }}$ of the $\mathrm{TiO}_{2} /$ MWCNT NCs-based DSSCs. In comparison to bare $\mathrm{TiO}_{2}$-based DSSCs, the IPCE value for T@0.1 C NCs-based DSSCs is 2.5 times higher. Similar to $I-V$ characterization, the loading of N719 dye and MWCNTs content in the $\mathrm{TiO}_{2}$ host lattice enhances the optical properties of the $\mathrm{TiO}_{2}$ host lattice, and it is better for the charge separation as well as the efficiency of the cells. ${ }^{28}$ In the end, IPCE response of T@0.1C NC with RuPc dye through INA was tested under the same operating conditions. It shows the two distinct absorption maxima, viz., between 300 to $400 \mathrm{~nm}$ and 600 to $700 \mathrm{~nm}$, for the conversion of solar to electrical current. The first region is dominated due to the absorption of $\mathrm{TiO}_{2}$, and the second wide region is analogous to RuPc only, with minimum absorption to that of the N719 dye. Overall, the IPCE value of $\mathrm{TiO}_{2} /$ MWCNTs NCs/N719 based DSSCs is almost three times that of the $\mathrm{TiO}_{2} / \mathrm{MWCNTs} \mathrm{NCs} / \mathrm{INA} /$ RuPc-based DSSCs. Because through carboxylic functional groups N719 is covalently connected to the surface of the $\mathrm{TiO}_{2}$ /MWCNTs NCs, the connectivity of the different moieties results in the high absorption capacity of the cells. Due to the absence of carboxylic functional moieties, RuPc was anchored on host materials through INA, but it may also build up the resistivity of the cells and hence decrease the overall conversion efficiency of the RuPc-based DSSCs. The lower power conversion efficiency confirms that, along with MWCNTs content, the proper connectivity between the dye and MWCNTs plays a dominant role in capturing as much incident light as possible by its absorption strength with host semiconducting material and overlaps that possible absorption with the solar spectrum.

\section{CONCLUSIONS}

Thin films of $\mathrm{TiO}_{2} /$ MWCNT NCs were successfully deposited on FTO-glass substrate using a binder-free doctor blade technique. The anchoring of $\mathrm{TiO}_{2}$ NPs to the surfaces of MWCNTs was confirmed by using HRTEM, FT-IR, Raman, and XPS analysis. With varying MWCNTs content in NCs, the structural parameters of the $\mathrm{TiO}_{2}$ host lattice were varied, which was also confirmed by Rietveld refinement studies (goodness of fit $=\sim 1.5$ ). The optical absorption edge of $\mathrm{TiO}_{2}$ extended toward the red region of the electromagnetic spectrum with MWCNTs, and the optical energy band gap of samples turned from 3.2 to $2.85 \mathrm{eV}$. The $\mathrm{TiO}_{2} /$ MWCNTs NCs are anchored with two different $\mathrm{Ru}(\mathrm{II})$-based dyes, viz., N719 and $\mathrm{RuPc}$, and these electrodes were used as photoanodes for efficient DSSCs. The different absorption and anchoring nature of sensitizers directly affected the solar energy power conversion efficiency of the devices. Among all devices, T@ $0.1 \mathrm{C}$ NCs with N719-based devices showed the highest $J_{\text {so }} V_{\text {oc }}$ FF, and $\eta(6.21 \%)$ as that of either other CNTs-based devices or the RuPc-based DSSCs device $(\eta=2.07 \%)$. The same materials were utilized toward the fabrication of solid-state DSSCs (using either p-type inorganic or p-type organic semiconductors as HTMs), and works are in progress in our lab.

\section{EXPERIMENTAL SECTION}

The commercial pristine MWCNTs were functionalized with the acid treatment method, ${ }^{50}$ and bare $\mathrm{TiO}_{2}$ NPs were synthesized by an earlier reported sol-gel method with slight modifications. ${ }^{51}$ The phthalocyanine (Pc) based $\mathrm{Ru}(\mathrm{II})$ complex $(\mathrm{RuPc})$ was prepared by using a literature method with some modifications. ${ }^{52}$ The detailed experimental conditions of all these materials have been provided in the Supporting Information.

Synthesis of $\mathrm{TiO}_{2} / \mathrm{MWCNTs}$ Nanocomposites (NCs). An in situ sol-gel method was used for synthesizing $\mathrm{TiO}_{2} /$ MWCNT NCs with varying content of MWCNTs. The functionalized MWCNTs were dispersed in deionized water (DW) using an ultrasonicator bath, and these MWCNTs were added directly during the synthesis of the $\mathrm{TiO}_{2} \mathrm{NPs}$ route after 
hydroxylation of titanium precursors. The blackish colored precipitate formed and was subsequently washed, dried, and annealed at $753 \mathrm{~K}$ for $2 \mathrm{~h}$. The different contents of MWCNTs such as $0.01,0.05,0.10 .25$, and 1.0 wt $\%$ were added to the titanium precursor, and then these samples are designated as T@0.01 C, T@0.05 C, T@0.1 C, T@0.25 C, and T@1.0 C, respectively.

Fabrication of DSSCs with $\mathrm{TiO}_{2} / \mathrm{MWCNTs}$ Photoanodes. Binder-free NCs were deposited on FTO glass electrode using the doctor-blade technique. Primarily, FTO glass substrates were washed thoroughly with water (with detergent), acetone, and finally in ethanol using an ultrasonicator bath. The cleaned glass substrates were annealed at $373 \mathrm{~K}$ for $30 \mathrm{~min}$. The NC powders were ultrasonically dispersed in both $N, N$-dimethylformamide (DMF) and acetonitrile $(\mathrm{ACN})$ for $1 \mathrm{~h}$ and $30 \mathrm{~min}$, respectively, and the upper organic layer was decanted. The remaining portion was stirred continuously to form slurry. This slurry was deposited on a cleaned FTO glass substrate using the doctor-blade method, and these films were sintered at $723 \mathrm{~K}$ for $2 \mathrm{~h}$. The deposited thin films were sensitized using, namely, N719 and RuPc dyes separately. In sensitization protocol, thin films were immersed in $0.3 \mathrm{mM} \mathrm{N719}$ dye solution (1:1 mixture of tertbutyl alcohol and ACN) for $18 \mathrm{~h}$ (room temp). The unbound dye was removed from the film after rinsing twice in a combination of tert-butyl alcohol and acetonitrile. The N719 dye-anchored photoelectrode was sandwiched between the platinum counter electrode (Pt/ITO) using $60 \mu \mathrm{m}$ thick sealing Surlyn sheet. Finally, the electrolyte $\left(1.0 \mathrm{M} \mathrm{LiI}+0.06 \mathrm{M} \mathrm{I}_{2}\right.$ in propylene carbonate) was impregnated and sealed (Scheme 1). The photovoltaic performance of the devices (with an active area of $0.25 \mathrm{~cm}^{2}$ ) was measured by the current-voltage (IV) and IPCE spectra. Similarly, the photovoltaic performance of the sandwich-type DSSCs with $\mathrm{TiO}_{2} /$ MWCNTs (T@0.1 C) photoelectrode, sensitized with RuPc dye, was also measured.

\section{ASSOCIATED CONTENT}

\section{S Supporting Information}

The Supporting Information is available free of charge on the ACS Publications website at DOI: 10.1021/acsomega.7b01316.

The thermal stability (TGA) and structural parameters of as-synthesized materials, position coordinates and atom occupancies of $\mathrm{TiO}_{2}, \mathrm{XRD}$ refined patterns of T@0.01 C, T@0.05 C, T@0.25 C, and T@1.00 C, MWCNTs composition (wt \%) as a function of optical energy band gap, and photoluminescence excitation spectra (PDF)

\section{AUTHOR INFORMATION}

\section{Corresponding Authors}

*E-mail: sddelekar7@gmail.com (Sagar Delekar).

*E-mail: dpanda@g.clemson.edu (Dr. Dillip K. Panda). Tel.: +91-231-2609100. Fax: +91-231-2692333.

\section{ORCID}

Sagar D. Delekar: 0000-0002-4510-305X

Naresh S. Dalal: 0000-0002-9996-6918

\section{Author Contributions}

${ }^{\#}$ S.D.D. and A.G.D. contributed equally

\section{Author Contributions}

The final version of the manuscript was approved by all authors.

\section{Notes}

The authors declare no competing financial interest.

\section{ACKNOWLEDGMENTS}

Authors, SDD and AGD, thank to University Grant Commission and Department of Science and Technology, New Delhi, India, for a Raman postdoctoral fellowship at the Florida State University (UGC-No. F 5-88/2014 (IC) dated 9 Sep 2014), Rajiv Gandhi National Research Fellowship (UGC No. F./2014-15/RGNF-2014-15D-SC-MAH-61438 dated, April 2014) and fast track research scheme for young scientists (DST-No.SR/FT/CS-137/2010). Author SDD also acknowledges the late Sir Harold Kroto, Department of Chemistry and Biochemistry, Florida State University, Tallahassee, for giving him an opportunity to work with him under the Raman fellowship.

\section{REFERENCES}

(1) Lewis, N. S.; Nocera, D. G. Powering the Planet: Chemical Challenges in Solar Energy Utilization. Proc. Natl. Acad. Sci. U. S. A. 2006, 103, 15729-15735.

(2) Li, C.; Wang, F.; Yu, J. C. Semiconductor/Biomolecular Composites for Solar Energy Applications. Energy Environ. Sci. 2011, $4,100-113$.

(3) Dumortier, M.; Tembhurne, S.; Haussener, S. Holistic Design Guidelines for Solar Hydrogen Production by Photo-Electrochemical Routes. Energy Environ. Sci. 2015, 8, 3614-3628.

(4) Chen, G.; Seo, J.; Yang, C.; Prasad, P. N. Nanochemistry and Nanomaterials for Photovoltaics. Chem. Soc. Rev. 2013, 42, 83048338.

(5) Grätzel, M. Photoelectrochemical Cells. Nature 2001, 414, 338344.

(6) Pastore, M.; De Angelis, F. Aggregation of Organic Dyes on $\mathrm{TiO}_{2}$ in Dye-Sensitized Solar Cells Models: An Ab Initio Investigation. ACS Nano 2009, 4, 556-562.

(7) Kakiage, K.; Aoyama, Y.; Yano, T.; Oya, K.; Fujisawa, J.-i.; Hanaya, M. Highly-Efficient Dye-Sensitized Solar Cells with Collaborative Sensitization by Silyl-Anchor and Carboxy-Anchor Dyes. Chem. Commun. 2015, 51, 15894-15897.

(8) Pazos-Outón, L. M.; Lee, J. M.; Futscher, M. H.; Kirch, A.; Tabachnyk, M.; Friend, R. H.; Ehrler, B. A Silicon-Singlet Fission Tandem Solar Cell Exceeding 100\% External Quantum Efficiency with High Spectral Stability. ACS Energy Lett. 2017, 2, 476.

(9) Kawashima, K.; Tamai, Y.; Ohkita, H.; Osaka, I.; Takimiya, K. High-Efficiency Polymer Solar Cells with Small Photon Energy Loss. Nat. Commun. 2015, 6, 10085.

(10) Zhang, J.; Peng, W.; Chen, Z.; Chen, H.; Han, L. Effect of Cerium Doping in the $\mathrm{TiO}_{2}$ Photoanode on the Electron Transport of Dye-Sensitized Solar Cells. J. Phys. Chem. C 2012, 116, 19182-19190.

(11) Rui, Z.; Chen, L.; Chen, H.; Ji, H. Strong Metal-Support Interaction in $\mathrm{Pt} / \mathrm{TiO}_{2}$ Induced by Mild Hcho and Nabh4 Solution Reduction and Its Effect on Catalytic Toluene Combustion. Ind. Eng. Chem. Res. 2014, 53, 15879-15888.

(12) Kim, S.-B.; Park, J.-Y.; Kim, C.-S.; Okuyama, K.; Lee, S.-E.; Jang, H.-D.; Kim, T.-O. Effects of Graphene in Dye-Sensitized Solar Cells Based on Nitrogen-Doped $\mathrm{TiO}_{2}$ Composite. J. Phys. Chem. C 2015, 119, 16552-16559.

(13) Wang, L.; Liu, H.; Konik, R. M.; Misewich, J. A.; Wong, S. S. Carbon Nanotube-Based Heterostructures for Solar Energy Applications. Chem. Soc. Rev. 2013, 42, 8134-8156.

(14) Chen, X.; Mao, S. S. Titanium Dioxide Nanomaterials: Synthesis, Properties, Modifications, and Applications. Chem. Rev. 2007, 107, 2891-2959.

(15) Dai, H.; Chen, G.; Zhou, C.; Fang, Q.; Fei, X. A Numerical Study of Ultraprecision Machining of Monocrystalline Silicon with Laser Nano-Structured Diamond Tools by Atomistic Simulation. Appl. Surf. Sci. 2017, 393, 405-416. 
(16) Nazeeruddin, M. K.; Bessho, T.; Cevey, L.; Ito, S.; Klein, C.; De Angelis, F.; Fantacci, S.; Comte, P.; Liska, P.; Imai, H. A High Molar Extinction Coefficient Charge Transfer Sensitizer and Its Application in Dye-Sensitized Solar Cell. J. Photochem. Photobiol., A 2007, 185, 331-337.

(17) Wang, X.; Xi, M.; Fong, H.; Zhu, Z. Flexible, Transferable, and Thermal-Durable Dye-Sensitized Solar Cell Photoanode Consisting of $\mathrm{TiO}_{2}$ Nanoparticles and Electrospun $\mathrm{TiO}_{2} / \mathrm{SiO}_{2}$ Nanofibers. ACS Appl. Mater. Interfaces 2014, 6, 15925-15932.

(18) Dembele, K. T.; Selopal, G. S.; Soldano, C.; Nechache, R.; Rimada, J. C.; Concina, I.; Sberveglieri, G.; Rosei, F.; Vomiero, A. Hybrid Carbon Nanotubes- $\mathrm{TiO}_{2}$ Photoanodes for High Efficiency Dye-Sensitized Solar Cells. J. Phys. Chem. C 2013, 117, 14510-14517.

(19) Ahn, J. Y.; Kim, J. H.; Moon, K. J.; Kim, J. H.; Lee, C. S.; Kim, M. Y.; Kang, J. W.; Kim, S. H. Incorporation of Multiwalled Carbon Nanotubes into $\mathrm{TiO}_{2}$ Nanowires for Enhancing Photovoltaic Performance of Dye-Sensitized Solar Cells Via Highly Efficient Electron Transfer. Sol. Energy 2013, 92, 41-46.

(20) O’Regan, B. C.; López-Duarte, I.; Martínez-Díaz, M. V.; Forneli, A.; Albero, J.; Morandeira, A.; Palomares, E.; Torres, T.; Durrant, J. R. Catalysis of Recombination and Its Limitation on Open Circuit Voltage for Dye Sensitized Photovoltaic Cells Using Phthalocyanine Dyes. J. Am. Chem. Soc. 2008, 130, 2906-2907.

(21) Ye, M.; Wen, X.; Wang, M.; Iocozzia, J.; Zhang, N.; Lin, C.; Lin, Z. Recent Advances in Dye-Sensitized Solar Cells: From Photoanodes, Sensitizers and Electrolytes to Counter Electrodes. Mater. Today 2015, $18,155-162$.

(22) Martín-Gomis, L.; Fernández-Lázaro, F.; Sastre-Santos, Á. Advances in Phthalocyanine-Sensitized Solar Cells (Pcsscs). J. Mater. Chem. A 2014, 2, 15672-15682.

(23) Muduli, S.; Lee, W.; Dhas, V.; Mujawar, S.; Dubey, M.; Vijayamohanan, K.; Han, S.-H.; Ogale, S. Enhanced Conversion Efficiency in Dye-Sensitized Solar Cells Based on Hydrothermally Synthesized $\mathrm{TiO}_{2}-\mathrm{MWCNT}$ Nanocomposites. ACS Appl. Mater. Interfaces 2009, 1, 2030-2035.

(24) Dembele, K.; Nechache, R.; Nikolova, L.; Vomiero, A.; Santato, C.; Licoccia, S.; Rosei, F. Effect of Multi-Walled Carbon Nanotubes on the Stability of Dye Sensitized Solar Cells. J. Power Sources 2013, 233, 93-97.

(25) Delekar, S.; Yadav, H.; Achary, S.; Meena, S.; Pawar, S. Structural Refinement and Photocatalytic Activity of Fe-Doped Anatase $\mathrm{TiO}_{2}$ Nanoparticles. Appl. Surf. Sci. 2012, 263, 536-545.

(26) Dinnebier, R. E. Powder Diffraction: Theory and Practice; Royal Society of Chemistry, 2008.

(27) Pan, D.; Jiao, J.; Li, Z.; Guo, Y.; Feng, C.; Liu, Y.; Wang, L.; Wu, M. Efficient Separation of Electron-Hole Pairs in Graphene Quantum Dots by $\mathrm{TiO}_{2}$ Heterojunctions for Dye Degradation. ACS Sustainable Chem. Eng. 2015, 3, 2405-2413.

(28) Yadav, S. K.; Mahapatra, S. S.; Cho, J. W.; Lee, J. Y. Functionalization of Multiwalled Carbon Nanotubes with Poly (Styrene-B-(Ethylene-Co-Butylene)-B-Styrene) by Click Coupling. J. Phys. Chem. C 2010, 114, 11395-11400.

(29) Sadhu, S.; Poddar, P. Template-Free Fabrication of HighlyOriented Single-Crystalline 1d-Rutile $\mathrm{TiO}_{2}$-MWCNT Composite for Enhanced Photoelectrochemical Activity. J. Phys. Chem. C 2014, 118, 19363-19373.

(30) Zhang, S.; Niu, H.; Lan, Y.; Cheng, C.; Xu, J.; Wang, X. Synthesis of $\mathrm{TiO}_{2}$ Nanoparticles on Plasma-Treated Carbon Nanotubes and Its Application in Photoanodes of Dye-Sensitized Solar Cells. J. Phys. Chem. C 2011, 115, 22025-22034.

(31) Yan, X.-b.; Tay, B. K.; Yang, Y. Dispersing and Functionalizing Multiwalled Carbon Nanotubes in $\mathrm{TiO}_{2}$ Sol. J. Phys. Chem. B 2006, $110,25844-25849$.

(32) Wu, X.; Chen, X.; Wang, J.; Liu, J.; Fan, Z.; Chen, X.; Chen, J. Functionalization of Multiwalled Carbon Nanotubes with Thermotropic Liquid-Crystalline Polymer and Thermal Properties of Composites. Ind. Eng. Chem. Res. 2010, 50, 891-897.

(33) Liu, Y.; Tang, A.; Zhang, Q.; Yin, Y. Seed-Mediated Growth of Anatase $\mathrm{TiO}_{2}$ Nanocrystals with Core-Antenna Structures for
Enhanced Photocatalytic Activity. J. Am. Chem. Soc. 2015, 137, 11327-11339.

(34) Koli, V. B.; Dhodamani, A. G.; Raut, A. V.; Thorat, N. D.; Pawar, S. H.; Delekar, S. D. Visible Light Photo-Induced Antibacterial Activity of $\mathrm{TiO}_{2}$-MWCNTs Nanocomposites with Varying the Contents of Mwcnts. J. Photochem. Photobiol., A 2016, 328, 50-58.

(35) Shevale, V. B.; Dhodamani, A. G.; Koli, V. B.; Barkul, R. P.; Jadhav, J. P.; Delekar, S. D. Efficient Degradation of Azorubin S Colourant in the Commercial Jam-Jelly Food Samples Using $\mathrm{TiO}_{2}-$ $\mathrm{CoFe}_{2} \mathrm{O}_{4}$ Nanocomposites in Visible Light. Mater. Res. Bull. 2017, 89, 79-88.

(36) Makowski, M. J.; Galhenage, R. P.; Langford, J.; Hemminger, J. C. Liquid-Jet X-Ray Photoelectron Spectra of $\mathrm{TiO}_{2}$ Nanoparticles in an Aqueous Electrolyte Solution. J. Phys. Chem. Lett. 2016, 7, 17321735.

(37) Zhang, Y.; Guerra-Nuñez, C.; Li, M.; Michler, J.; Park, H. G.; Rossell, M. D.; Erni, R.; Utke, I. High Conformity and Large Domain Monocrystalline Anatase on Multiwall Carbon Nanotube Core-Shell Nanostructure: Synthesis, Structure, and Interface. Chem. Mater. 2016, 28, 3488-3496.

(38) Agarwala, S.; Kevin, M.; Wong, A.; Peh, C.; Thavasi, V.; Ho, G. Mesophase Ordering of $\mathrm{TiO}_{2}$ Film with High Surface Area and Strong Light Harvesting for Dye-Sensitized Solar Cell. ACS Appl. Mater. Interfaces 2010, 2, 1844-1850.

(39) Kang, C.; Jing, L.; Guo, T.; Cui, H.; Zhou, J.; Fu, H. Mesoporous $\mathrm{SiO}_{2}$-Modified Nanocrystalline Tio2 with High Anatase Thermal Stability and Large Surface Area as Efficient Photocatalyst. J. Phys. Chem. C 2008, 113, 1006-1013.

(40) Parveen, N.; Ansari, M. O.; Cho, M. H. Route to High Surface Area, Mesoporosity of Polyaniline-Titanium Dioxide Nanocomposites Via One Pot Synthesis for Energy Storage Applications. Ind. Eng. Chem. Res. 2016, 55, 116-124.

(41) Xie, L.-Q.; Ding, D.; Zhang, M.; Chen, S.; Qiu, Z.; Yan, J.-W.; Yang, Z.-L.; Chen, M.-S.; Mao, B.-W.; Tian, Z.-Q. Adsorption of Dye Molecules on Single Crystalline Semiconductor Surfaces: An Electrochemical Shell-Isolated Nanoparticle Enhanced Raman Spectroscopy Study. J. Phys. Chem. C 2016, 120, 22500-22507.

(42) De Angelis, F.; Fantacci, S.; Mosconi, E.; Nazeeruddin, M. K.; Grätzel, M. Absorption Spectra and Excited State Energy Levels of the N719 Dye on $\mathrm{TiO}_{2}$ in Dye-Sensitized Solar Cell Models. J. Phys. Chem. C 2011, 115, 8825-8831.

(43) Martin-Gomis, L.; Fernandez-Lazaro, F.; Sastre-Santos, A. Advances in Phthalocyanine-Sensitized Solar Cells (Pcsscs). J. Mater. Chem. A 2014, 2, 15672-15682.

(44) Yang, M.; Ding, B.; Lee, S.; Lee, J.-K. Carrier Transport in DyeSensitized Solar Cells Using Single Crystalline $\mathrm{TiO}_{2}$ Nanorods Grown by a Microwave-Assisted Hydrothermal Reaction. J. Phys. Chem. C 2011, 115, 14534-14541.

(45) Yang, W.; Vlachopoulos, N.; Boschloo, G. Impact of Local Electric Fields on Charge-Transfer Processes at the $\mathrm{TiO}_{2} /$ Dye/ Electrolyte Interface. ACS Ener. Lett. 2017, 2, 161-167.

(46) Sajedi Alvar, M.; Javadi, M.; Abdi, Y.; Arzi, E. Enhancing the Electron Lifetime and Diffusion Coefficient in Dye-Sensitized Solar Cells by Patterning the Layer of $\mathrm{TiO}_{2}$ Nanoparticles. J. Appl. Phys. 2016, 119, 114302.

(47) Wang, J.; Lin, Y.; Pinault, M.; Filoramo, A.; Fabert, M.; Ratier, B.; Bouclé, J.; Herlin-Boime, N. Single-Step Preparation of $\mathrm{TiO}_{2} /$ MWCNT Nanohybrid Materials by Laser Pyrolysis and Application to Efficient Photovoltaic Energy Conversion. ACS Appl. Mater. Interfaces 2015, 7, 51-56.

(48) Bhande, S. S.; Ambade, R. B.; Shinde, D. V.; Ambade, S. B.; Patil, S. A.; Naushad, M.; Mane, R. S.; Alothman, Z.; Lee, S.-H.; Han, S.-H. Improved Photoelectrochemical Cell Performance of Tin Oxide with Functionalized Multiwalled Carbon Nanotubes-Cadmium Selenide Sensitizer. ACS Appl. Mater. Interfaces 2015, 7, 25094-25104.

(49) Liu, J.; Kuo, Y.-T.; Klabunde, K. J.; Rochford, C.; Wu, J.; Li, J. Novel Dye-Sensitized Solar Cell Architecture Using $\mathrm{TiO}_{2}$-Coated Vertically Aligned Carbon Nanofiber Arrays. ACS Appl. Mater. Interfaces 2009, 1, 1645-1649. 
(50) Koli, V.; Dhodamani, A.; More, K.; Acquah, S. F.; Panda, D. K.; Pawar, S.; Delekar, S. A Simple Strategy for the Anchoring of Anatase Titania on Multi-Walled Carbon Nanotubes for Solar Energy Harvesting. Sol. Energy 2017, 149, 188-194.

(51) Koli, V. B.; Dhodamani, A. G.; Delekar, S. D.; Pawar, S. H. In Situ Sol-Gel Synthesis of Anatase $\mathrm{TiO}_{2}$-MWCNTs Nanocomposites and Their Photocatalytic Applications. J. Photochem. Photobiol., A 2017, 333, 40-48.

(52) Morandeira, A.; López-Duarte, I.; O’Regan, B.; Martinez-Diaz, M. V.; Forneli, A.; Palomares, E.; Torres, T.; Durrant, J. R. Ru (Ii)Phthalocyanine Sensitized Solar Cells: The Influence of CoAdsorbents Upon Interfacial Electron Transfer Kinetics. J. Mater. Chem. 2009, 19, 5016-5026. 